
ISSN : 2615-1995, E-ISSN : 2615-0654

J. Madani., Vol. 2, No. 2, September 2019 (314 - 323)

(C)2018 Lembaga Kajian Demokrasi

dan Pemberdayaan Masyarakat (LKD-PM)

\title{
Pengaruh Efektivitas Manajerial dan Kepercayaan Terhadap Kinerja Guru SMA Bekasi
}

\author{
Moh Khoiri \\ Fakultas Keguruan dan Ilmu Pendidikan, Universitas Pamulang \\ dosen01669@unpam.ac.id
}

\begin{abstract}
Abstrak
Penelitiannya dilakukan untuk mengetahui apakah ada pengaruh antara (1) efektivitas manajerial, (2) kepercayaan, (3) kinerja guru sekolah dasar di kecamatan branchbungin di Bekasi. Penelitian dilakukan dengan metode survey kausul atas variabel yang dikemukakan dan menggunakan Technicque Path Analysis. Penelitian ini memiliki sampel 97 guru di 12 sekolah dasar di Cabangbungin, Bekasi yang dipilih dengan menggunakan rumus Slovin. Dari hasil penelitian ini ditemukan bahwa : yang pertama, adanya pengaruh positif antara efektivitas manajerial pada kinerja guru di sekolah. Yang kedua, adanya pengaruh positif antara kepercayaan dan kinerja guru di sekolah. Dan yang ketiga, terdapat pengaruh positif antara efektivitas manajerial dan kepercayaan guru di sekolah.
\end{abstract}

Kata Kunci: Efektivitas Manajerial, Kepercayaan, Kinerja Guru

\begin{abstract}
The research was conducted to find out whether there was an influence between (1) managerial planning, (2) trust, (3) improving the performance of elementary school teachers in the branchbungin sub-district in Bekasi. The study was conducted using a survey of the causal survey of the variables raised and using Technicque Path Analysis. This study had a sample of 97 teachers in 12 primary schools in Cabangbungin Bekasi selected using the Slovin formula. From the results of this study found that: first, there is a positive influence between managerial ability on teacher performance in school. Secondly, the positive influence between teacher trust and performance in schools. And the third, is a positive influence between managerial and trust in the school.
\end{abstract}

Keywords: Managerial Effectiveness, Trust and Job Performance

\section{PENDAHULUAN}

\section{Latar Belakang}

Pendidikan penentu perubahan suatu negara. Bagaimana tidak, cerdasnya suatu negara dapat merubahan arah suatu bangsa. Dapat menggambarkan kualitas pendidikan suatu negara tersebut. Pada dasarnya dari semua ini pendidikan sangat diutamakan dalam suatu negara agar memiliki daya saing yang hebat. Selanjutnya jika kita membahas kualitas pendidikan Indonesia maka kita sejenak kembali pada sejarah kurikulum pendidikan Indonesia. Dari sejarah tersebut kita sudah mengalami pergantian kurikulum sebanyak sepuluh kali. Namun sampai saat ini tidak memberikan dampak yang segnifikan pada perubahan pembangunan bangsa, minimal cara berpikir dan bersikap sangat baik.

Apapun upaya yang dilakukan oleh pemerintah tersebut dalam rangka meningkatkan kualitas kehidupan manusia yang berkualitas dan me- 
miliki daya saing yang baik. Kemudian jika kita melihat realita pendidikan Indonesia maka masih sangat banyak yang harus di soroti seperti terkait dengan kinerja guru yang sampai saat ini masih belum menjawab tantangkan kita sebagai bangsa Indonesia. Selanjutnya banyak kasus-kasus yang ditemukan di berbagai tempat pendidikan tentang kinerja guru yang dinilai tidak optimal. Ketidakoptimalan guru dalam bekerja itu tentu banyak faktor yang dapat mempengaharuhi hal tersebut. Salah satu faktor yang membut guru tidak memiliki kinerja yang baik adalah mengenai upah atau gaji yang terima. Dalam hasil penelitian manajemen banyak ditemukan hasil penelitian yang menunjukkan bahwa guru tidak bekerja dengan baik dengan kata lain bisa dikatakan kinerjanya rendah karena faktor gaji yang diterimanya selama bekerja. Meksi dalam teori manajemenpun yang membuat guru tidak memiliki kinerja yang baik bukan karena gaji saja namun masih banyak variabel yang lain yang dapat mempengaruhi rendahnya kinerja guru.

Kembali pada pentingya kinerja guru yang selama ini menjadi sorotan publik karena pendidikan dinilai menjadi tolak ukur Indonesia dalam membangun bangsa secara keseluruhan. Guru sangat penting perannya dalam membangun bangsa Indonesia. Apa lagi dengan kondisi global saat ini yang membuat kita harus siap dengan persaingan global yang sangat ketat dari berbagai lini kehidupan manusia. Guru seharusnya memiliki semangat bekerja dan semangat mengabdi dalam membangun manusia. Hanya saja sampai saat ini penghargaan pemerintah terhadap guru dinilai masih rendah atau ketidakpedulian pemerintah selama ini dinilai kurang tepat.

Harapan bangsa ini satu-satunya adalah dengan meningkatnya kualitas pendidikan Indonesia. Jika Jepang dan negara-negara di Asia mampu memiliki daya saing bahkan mampu menguasai pasar dunia, pertanyaannya mengapa Indonesia yang memiliki segalanya tidak mampu membuat dunia ini bergantung pada Indonesia bahkan kebalikannya Indonesai sebagai bangsa besar bergantung pada bangsa lain.

Harapan yang mendasar bangsa Indonesai saat ini adalah mampu memiliki daya saing yang hebat dan mampu berdiri di kaki bangsa sendiri. Harapan itu masih ada dan harus memiliki keyakinan bahwa bangsa Indonesia suatu saat akan menguasai dunia. Ini bisa dilakukan dengan satu cara yaitu tingkatkan kualitas pendidikan dengan membuat manajemen baru yang membuat guru sebagai tenaga pendidik mampu menghasilkan generasi emas sesuai yang dicita-citakan bangsa Indonesia dimana saat genap seratus tahun Indonesia merdeka kita sudah menjadi bangsa yang mandiri, bangsa yang tak lagi bergantung pada siapapun, masyarakatnya mampu saling menghargai satu sama lain, perbedaan yang selama ini terjadi harus tetap kokoh dan menjunjung tinggi nilai-nilai Pancasila. Jika semua ini terjadi maka kita akan mampu menguasai dunia dari berbagai aspek kehidupan.

Terkadang ukuran untuk mengatakan bahwa baiknya pendidikan suatu bangsa adalah dengan prestasi pendidikan yang didapatkan. Namun tidak hanya itu untuk melihatnya kualitas pendidikan itu dengan kinerja guru. Apapun kurikulum yang akan diterapkan jika guru tetap memiliki kinerja yang kurang baik maka tidak akan mampu menghasilkan kualitas yang baik. Untuk itu beberapa penelitian tentang manajemen pendidikan berpendapat bawah kinerja guru sangat penting untuk meningkatkan kualitas manusia di suatu negara.

Menyikapi itu, kinera guru harus ditingkatkan lagi dengan memberikan hak-hak yang seharusnya diterima oleh guru. Akhir-akhir ini guru menjadi perbincangan karena masih ada guru yang memiliki kinerja yang sangat rendah dalam mengajar padahal tunjangan guru dan gaji guru sudah diberikan sesuai dengan sistem pengajian yang berlaku. Bekasi sebagai kota yang relatif dekat dengan Jakarta masih memiliki sistem gaji yang berbeda dengan Jakarta yang sudah dianggap mampu mensejahterakan para guru. Kinerja guru-guru di Bekasi masih dianggap rendah dengan banyaknya kasus yang diterima. Seperti yang di lansir di media sosial pemerintah Bekasi melakukan PKG penilaian kinerja guru. Ini merupakan bentuk pernyataan kepala dinas pendidikan kota Bekasi maksud diadakannya penilaian kinerja guru. PKG ini 
akan berjalan dengan baik, jika peningkatan mutu pendidikan bisa dilakukan dengan baik pula, seperti peningkatan kualifikasi pendidikan. Selain itu pula, jelas Ali, Disdik Kota Bekasi juga telah memberikan penghasilan tambahan bagi guru berupa tunjangan sertifikasi yang sudah digulirkan sejak tahun 2006 yang lalu, seperti honor tambahan satu kali gaji setiap bulannya. Penilaian kinerja guru ini dilakukan karena didasari tidak adanya perubahan mindset berpikir, bagi mereka yang sudah memiliki sertifikasi akan rasa tanggung jawab akan tugas pokok mereka.

Berikut faktor-faktor yang mempengaruhi kinerja guru: a, motivasi kerja guru, motivasi kerja guru dinilai sangat penting untuk memastikan guru tersebut bekerja dengan baik. b, etos kerja, inipun tak kalah pentingnya karena berkaitan dengan rasa ingin bekerja atas dorongan diri sendiri sangat penting dimiliki oleh guru, c, lingkungan kerja yang baik, jika guru memiliki lingkungan kerja yang kurang baik maka akan memiliki dampat pada kinerja guru.

Kondisi rendahnya kinerja guru yang terjadi saat ini, menjadikan peneliti tertarik untuk meneliti lebih dalam lagi mengenai kinerja guru.

\section{Kajian Pustaka}

Kinerja

Jason A. Colquitt ( 2015: 35 ) job performance is formally defined as the value of the set of employee behaviors that contribute, either positivly or negativly, to organizational goal accomplishment". Menurut Colquitt konsep kinerja bisa diartikan adanya seperangkat nilai pada individu pekerja baik itu secara positif maupun negatif dalam rangka mencapai tujuan organisasi. Konsep ini mengedepankan pada perilaku seseorang dalam bekerja yang pada dasarnya harus dituntut untuk tetap mengarah pada kemajuan organisasi secara positif. Begitupun dengan John M.Ivancevich (2014: 172) job performance a set of employee work related behavior designed to accomplish organizational goals". Jika memahami konsep kinerja menurut $\mathrm{M}$. Ivancevich ini bahwa kinerja adalah suatu perilaku yang berkaitan langsung dengan pekerjaan karyawan yang hasil kerjanya tersebut merupakan pekerjaan yang sudah teren- cana dengan baik. Konsep ini menegaskan pada suatu pekerjaan memang memerlukan suatu perencanaan yang baik agar capaian organisasi akan mudah tercapai dengan baik. Selanjutnya James L.Gibson ( 2012: 374 ) juga mengemukakan bahwa job performance the outcomes of jobs that relate to the purposes of the organization such as quality, efficiency and other criteria of effevtiveness".

Penulis sangat sependapat dengan konsep ini jika bicara kinerja maka bicara akan hasil dari keseluruhan pekerjaan baik secara kuantitatif maupun kualitatif dari apa yang sudah dikerjaan beda halnya dengan Steve M.Jex ( 2002: 34 ) ikut mendefinisikan bahwa job performance is the set of worker's behaviors that can be monitored, measured, and assessed achievement in individual level. Sama halnya dengan beberapa konsep diatas bahawa Steve ini bicara ranah perilaku kerja karyawan yang bisa dilihat dan dinilai atas apa yang yang sudah dikerjakan oleh karyawan. Tentu setiap pekerjaan tersebut bisa bicara perilaku pekerjaan tersebut juga bisa bicara tentang hasil yang secara nyata bisa dilihat.

Berdasarkan dari beberapa konsep kinerja di atas, dapat disentesiskan bahwa kinerja adalah hasil dari pekerjaan seseorang yang melibatkan segala perilakunya untuk tetap memajukan organisasinya baik secara kualitatif mampun kuantitatif dengan ketetapan indikator. (1) kuantitas pekerjaannya, (2) kualitas pekerjaannya, (3) kemampuan kerjasamanya, (4) kehandalannya, (5) inisiatif kerja.

\section{Efektivitas Manajerial}

Laurie J. Mullins ( 2005 : 260 ) mendefinisikan managerial effectiveness is concerned with doing the right things and relates to output of the job and what the manager actually achieves. Jika memahami definisi yang dikemukakan Laurie tentang Efektivitas Manajerial ini adalah hal yang berkaitan tentang sesuatu yang dilakukan oleh manajer untuk mencapai tujuan-tujuannya pada organisasi. Sebenarnya apapun jenis organisasi yang dikelolanya dimanapun itu kemampuan manajer itu sangat menentukan kemajuan organisasi. Dimana Laurie J. Mullins (2005 : 263) juga menjelaskan lebih lanjut bahwa managerial 
effectiveness has to be defined in terms of output rather than input, by what a manager achieves rather than by what he does. Pada konsep ini pemimpin diminta untuk fokus pada hasil dari apa yang sudah dilakukan aoleh pemimpin organisasi. organisasi sangat bergantung pada kemampuan pemimpin dalam hal ini tentu bagaimana seorang pemimpin mampu melakukan hal yang efektif dalam melakukan keputusan-keputusan yang akan menentukan arah organisasi. Dipihak lain ada Shalini Srivastava (2011:330) juga mendefinisikan bahwa managerial effectiveness is nothing more than the output, and it is dependent upon the output with regards to one's position in the organization. Pemahaman ini adalah tentang Efektivitas manajerial yang tidak lebih dari output atau hasil dari apa yang sudah dikerjakan manajer. Sedangkan Umesh K. Bamel (2011: 69-78) mengatakan results and consequences, bringing about effects, in relation to purpose, and giving validity to particular activities. Ini berkaitan dengan sebuah hasil yang sudah dilakukan oleh manajer tentu dengan penuh dengan penuh konsekuensi, dampak yang secara langsung berkaitan dengan tujuan organisasi.

Dari beberapa konsep diatas dapat disintesiskan bahw efektivitas manajerial adalah suatu yang berkaitan dengan keberhasilan atas pekerjaan dan ketepatan dalam melaksanakan fungsinya manajer, dengan indikator: (1) Keberhasilan mencapai tujuan, (2) Ketepatan memanfaatkan SDM, (3) Efektif dalam berkoordinasi, dan (4) Tepat dalam mengawasi.

\section{Kepercayaan}

Salah satu variabel yang tidak bisa anggap biasa adalah tentang kepercayaan. Dimana Jason A. Colquitt ( 2015 : 204 ) mendefiniskan bahwa Trust is defined as the willingness to be vulnerable to an authority based on positive expectations about the authority's actions and intentions. Untuk mendapatkan harapan yang baik pada pemilik otoritas organisasi sangat diperlukan kepercayaan yang positif pada pelaku kerja. Untuk itu dalam organisasi ada harapan yang ingin dicapai melalui orang lain yakni karyawan yang harus memberikan seluruh kemampuannya pada organiasi sehingga organisasi memiliki rasa dengan kepercayaan pada karyawan. Merawat dan menciptakan kepercayaan memang sangat perlu agar semua komponen organisasi saling mendapatkan kepercayaan satu sama lain sehingga perilaku kerja dengan mudah dilakukan sehingga produktivitas dan kinerja organisasi dapat dipastikan bisa dengan mudah terukur dengan baik. Sedangkan Steven L. Mc Shane (2010 : 113) juga mendefinisikan Trust refers to positive expectations one person has toward another person in situations involving risk. Trust means putting faith in the other person or group. Dalam kontek pekerjaan tentu semua manajemen dan anggota organisasi mengharapkan saling mendapatkan pekerjaan agar situasi dalam bekerja dalam dengan dengan mudah tercapai dengan baik. Salah satu tokoh ilmu manajemen yakni Stephen P Robbins ( 2014 : 575 ) mendefinisikan bahwa Trust is defined as the belief in the integrity, character and ability of a leader". Research has identified five dimension that make up the concept of trust; integrity, competence, consistency, loyalty and openness. Disini Robins lebih mengedepankan bahwa kepercayaan itu berkaitan dengan integritas dalam bekerja, karakter dalam bekerja dan kemampuan dalam memimpin. Selanjutnya Stephen P Robbins (2014 : 385) juga mendefinisikan Trust is a psychological state that exists when you agree to make yourself vulnerable to another because you have positive expectations about how things are going to turn out. Sebenarnya kepercayaan sangat erat kaitannya dengan keadaan psikologis yang mana setiap orang harus membuktikannya dengan tindakannya sendiri. Sebenarnya Robins juga ingin menggambarkan bahwa setiap orang yang tergabung dalam suatu organiasi harus secara individu berusaha menciptakan kepercayaannya satu sama lain. Keadaan ini sangat diharapkan mengingat organisasi dimanapun harus salah menciptakan kepercayaan. Dilanjutkan oleh Jennifer M George, Gareth Jones (2014 : 116) Trust is the willingness of one person or group to have faith or confidence in the goodwill of another person, even though this puts them at risk (because the other might act in a deceitful way). Dalam konsep ini hal yang harus digarisbawahi adalah 
bahwa mempercayai seseorang memang sangat sulit dan mendapatkan kepercayaan itu tidaklah mudah. Kepercayaan memang harus secara itu untuk dapat diamati dan dilihat dari banyak aspek.

Dari penjelasan di atas banyak konsep kepercayaan yang dikemukakan oleh para ahli, maka dapat disinertesiskan bawah kepercayaan adalah keyakinan seseorang yang timbul dari apa yang dilihatnya secara sadar memiliki rasa pengharapan yang penuh dari apa yang dilakukannya pada kemajuan organisasi dengan indikator: (1) Integritas dalam bekerja, (2) Kompetensi yang didapatkan, (3) Konsistensi dalam berperilaku, (4) Loyalitas dalam bekerja, dan (5) Keterbukaan dalam bekerja.

\section{METODE}

Penelitian ini bertujuan untuk menguji apakah ada pengaruh langsung; (1) Efektivitas Manajerial terhadap kinerja guru , (2) kepercayaan pada kinerja, dan (3) Efektivitas Manajerial pada kepercayaan. Selanjutnya penelitian ini menggunakan metode survei tentu dengan pendekatan teknik analisis jalur. Penelitian ini dilaksanakan di SD Negeri Kecamatan Cabangbungin Kabupaten Bekasi. Dimana populasi penelitian ini sejumlah 128 guru. sedangkan sampel dari penelitian sebayak 97 guru. Maka analisa data untuk pengujian hipotesis ini akan dilakukan dengan cara menggunakan teknik analisis jalur, yakni teknik yang diterapkan untuk menjelaskan apakah ada pengaruh antara variabel-variabel penelitian tersebut. Sebelum itu yang dilakukan peneliti melaksanakan analisis jalur, dilanjut dengan uji signifikan regresi dan yang terakhir dengan uji linearitas regresi sebagai prasyarat uji statistik dilakukan pengujian penormalan data atas masing-masing variabel-variabel penelitian dengan Uji-Liliefors, Statistik inferensial yaitu digunakan untuk menguji hipotesis pengaruh antar variabel dengan menggunakan tehnik analisis jalur.

\section{HASIL dan PEMBAHASAN}

\section{A. Deskripsi Data}

Penjelasan pada bagian ini diawali dari deskripsi data bagian data variabel $\mathrm{X}_{3}$ (Kinerja) sebagai variabel akhir atau sering disebut endogenous variabel, selanjutnya dengan variabel $\mathrm{X}_{1}$ (Efektivitas Manajerial) disebut sebagai variabel exsogenous dan yang terakhir variabel $\mathrm{X}_{2}$ (Kepercayaan) adalah sebagai variabel endogenous perantara. Maka deskripsi dari masingmasing variabel ini dapat disajikan secara berturut-turut yakni dari variabel $\mathrm{X}_{3}, \mathrm{X}_{1}$, dan $\mathrm{X}_{2}$.

1. Kinerja

Peneliti mendapatkan dapat data atas survei yang dilakukan dan diolah dalam statistika ke dalam daftar distribusi frekuensi, banyaknya kelas dihitung menurut aturan Sturges, diperoleh delapan kelas dengan nilai skor maksimum 146 dan skor minimum 117, sehingga rentang skor sebesar 29. Berdasarkan hasil perhitungan statistik deskriptif diperoleh bahwa data efektivitas kerja mempunyai nilai rata-rata (mean) sebesar 132,98 dengan nilai standar deviasi 5,45 dimana nilai variansnya sebesar 29,6871 nilai median 132,93 dan nilai modus sebesar 131,43 . Pengelompokkan data dapat terlihat pada tabel distribusi frekuensi sebagai berikut.

\begin{tabular}{|c|c|c|c|c|c|c|}
\hline \multicolumn{5}{c}{ Tabel 1. Distribusi Frekuensi Data Kinerja } \\
\hline \multirow{2}{*}{ No } & $\begin{array}{c}\text { Kelas } \\
\text { Interval }\end{array}$ & \multicolumn{2}{|c|}{ Batas } & \multicolumn{3}{c|}{ Frekuensi } \\
\cline { 3 - 7 } & Bawah & Atas & Absolut & Komulatif & Relatif \\
\hline 1 & $117-120$ & 116,5 & 120,5 & 3 & 3 & $3,09 \%$ \\
\hline 2 & $121-124$ & 120,5 & 124,5 & 3 & 6 & $3,09 \%$ \\
\hline 3 & $125-128$ & 124,5 & 128,5 & 9 & 15 & $9,28 \%$ \\
\hline 4 & $129-132$ & 128,5 & 132,5 & 31 & 46 & $31,96 \%$ \\
\hline 5 & $133-136$ & 132,5 & 136,5 & 23 & 69 & $23,71 \%$ \\
\hline 6 & $137-140$ & 136,5 & 140,5 & 21 & 90 & $21,65 \%$ \\
\hline 7 & $141-144$ & 140,5 & 144,5 & 6 & 96 & $6,19 \%$ \\
\hline 8 & $145-148$ & 144,5 & 148,5 & 1 & 97 & $1,03 \%$ \\
\hline \multicolumn{7}{|c|}{} \\
\hline
\end{tabular}

Dengan memperhatikan tabel di atas, maka selanjutnya dibuat histogram. Dalam histogram tersebut ada dua sumbu yang diperlukan yakni yakni sumbu vertikal untuk sumbu frekuensi absolut, dan selanjutnya 
sumbu horizontal sebagai sumbu atas skor kinerja. Selanjutnya pada sumbu horizontal terdapat batas-batas kelas interval yakni mulai dari 116,5 sampai dengan 148,5. Angka-angkat tersebut tersebut diperoleh dengan mengurangkan angka 0,5 dari data terkecil dan menambahkan angka 0,5 dari setiap batas kelas yangdilihat dari batas tertinggi. Sedangkan grafik histogram dapat dilihat dari sebaran data skor kinerja seperti tertera dalam gambar dibawah ini.

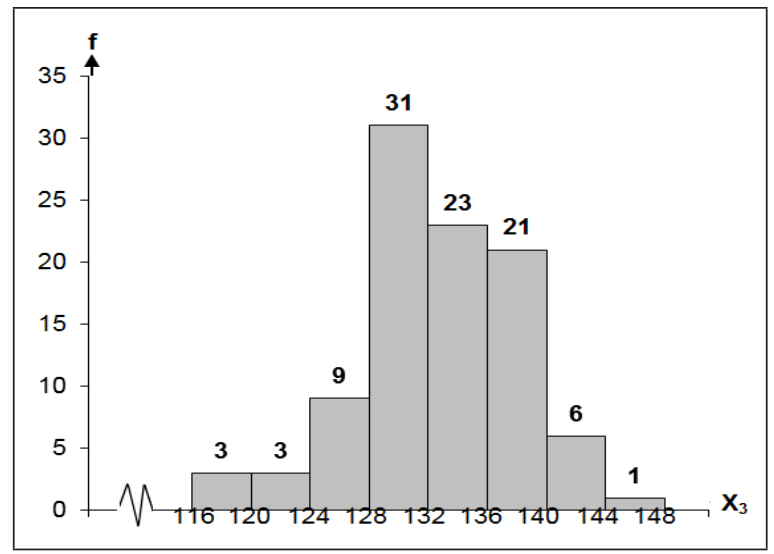

Gambar 1. Histogram Distribusi Data Kinerja

2. Efektivitas Manajerial

Data efektivitas manajerial memiliki data rentang skor teoretik dari 34 sampai 170 dan rentang skor empiris antara 127 sampai dengan 155, sehingga rentang skor sebesar 28. Hasil perhitungan data diperoleh ratarata sebesar 140,39; simpangan baku sebesar 4,97; varians sebesar 24,6574; median sebesar 140,50; dan modus sebesar 140,79. Selanjutnya data efektivitas manajerial disajikan dalam bentuk distribusi frekuensi seperti pada tabel berikut:

Tabel 2. Distribusi Frekuensi Data Efektivitas Manajerial

\begin{tabular}{|c|c|c|c|c|c|c|}
\hline \multirow{2}{*}{ No } & \multirow{2}{*}{$\begin{array}{l}\text { Kelas } \\
\text { Interval }\end{array}$} & \multicolumn{2}{|c|}{ Batas } & \multicolumn{3}{|c|}{ Frekuensi } \\
\hline & & Bawah & Atas & Absolut & Komulatif & Relatif \\
\hline 1 & $127-130$ & 126,5 & 130,5 & 2 & 2 & $2,06 \%$ \\
\hline 2 & $131-134$ & 130,5 & 134,5 & 9 & 11 & $9,28 \%$ \\
\hline 3 & $135-138$ & 134,5 & 138,5 & 21 & 32 & $21,65 \%$ \\
\hline 4 & $139-142$ & 138,5 & 142,5 & 33 & 65 & $34,02 \%$ \\
\hline 5 & $143-146$ & 142,5 & 146,5 & 24 & 89 & $24,74 \%$ \\
\hline 6 & $147-150$ & 146,5 & 150,5 & 6 & 95 & $6,19 \%$ \\
\hline 7 & $151-154$ & 150,5 & 154,5 & 1 & 96 & $1,03 \%$ \\
\hline 8 & $155-158$ & 154,5 & 158,5 & 1 & 97 & $1,03 \%$ \\
\hline & & & & 97 & & $100 \%$ \\
\hline
\end{tabular}

Dengan memperhatikan tabel di atas, maka selanjutnya dibuat histogram. Dalam histogram tersebut ada dua sumbu yang diperlukan yakni yakni sumbu vertikal untuk sumbu frekuensi absolut, dan selanjutnya sumbu horizontal sebagai sumbu atas skor Efektivitas Manajerial. Selanjutnya pada sumbu horizontal terdapat batas-batas kelas interval yakni mulai 126,5 sampai 158,5. Angka-angkat tersebut tersebut diperoleh dengan mengurangkan angka 0,5 dari data terkecil dan menambahkan angka 0,5 dari setiap batas kelas yangdilihat dari batas tertinggi. Sedangkan grafik histogram dapat dilihat dari sebaran data skor Efektivitas Manajerial seperti tertera dalam gambar dibawah ini.

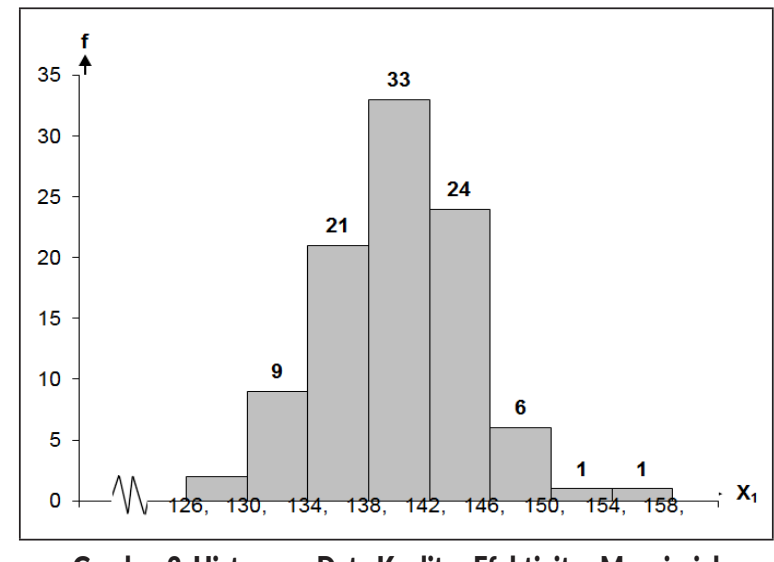

Gambar 2. Histogram Data Kualitas Efektivitas Manajerial

3. Kepercayaan

Data kepercayaan mempunyai rentang skor teoretik antara 34 sampai 170, dan rentang skor empiris antara 130 sampai dengan 159, sehingga rentang skor sebesar 29. Hasil perhitungan data diperoleh rata-rata sebesar 145,32; simpangan baku sebesar 5,08; varians sebesar 25,8447; median sebesar 145,56; dan modus sebesar 146,14 . Selanjutnya data kepercayaan disajikan dalam bentuk distribusi frekuensi seperti pada tabel berikut:

\begin{tabular}{c|c|c|c|c|c|c|}
\hline \multicolumn{5}{c}{ Tabel 3. Distribusi Frekuensi Skor Kepercayaan } \\
\cline { 4 - 7 } No & $\begin{array}{c}\text { Kelas } \\
\text { Interval }\end{array}$ & \multicolumn{2}{|c|}{ Batas } & \multicolumn{3}{c}{ Frekuensi } \\
\cline { 3 - 7 } & Bawah & Atas & Absolut & Komulatif & Relatif \\
\hline 1 & $130-133$ & 129,5 & 133,5 & 4 & 4 & $4,12 \%$ \\
\hline 2 & $134-137$ & 133,5 & 137,5 & 1 & 5 & $1,03 \%$ \\
\hline 3 & $138-141$ & 137,5 & 141,5 & 14 & 19 & $14,43 \%$ \\
\hline
\end{tabular}




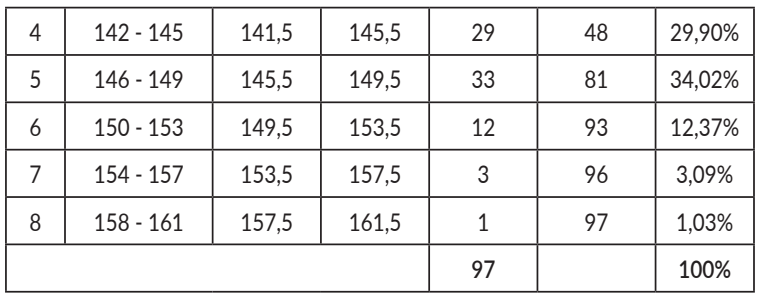

Dengan memperhatikan tabel di atas, maka selanjutnya dibuat histogram. Dalam histogram tersebut ada dua sumbu yang diperlukan yakni yakni sumbu vertikal untuk sumbu frekuensi absolut, dan selanjutnya sumbu horizontal sebagai sumbu atas skor kepercayaan. Selanjutnya pada sumbu horizontal terdapat batas-batas kelas interval yakni mulai dari 129,5 sampai 161,5 . Angkaangkat tersebut tersebut diperoleh dengan mengurangkan angka 0,5 dari data terkecil dan menambahkan angka 0,5 dari setiap batas kelas yangdilihat dari batas tertinggi. Sedangkan grafik histogram dapat dilihat dari sebaran data skor kepercayaan seperti tertera dalam gambar dibawah ini.

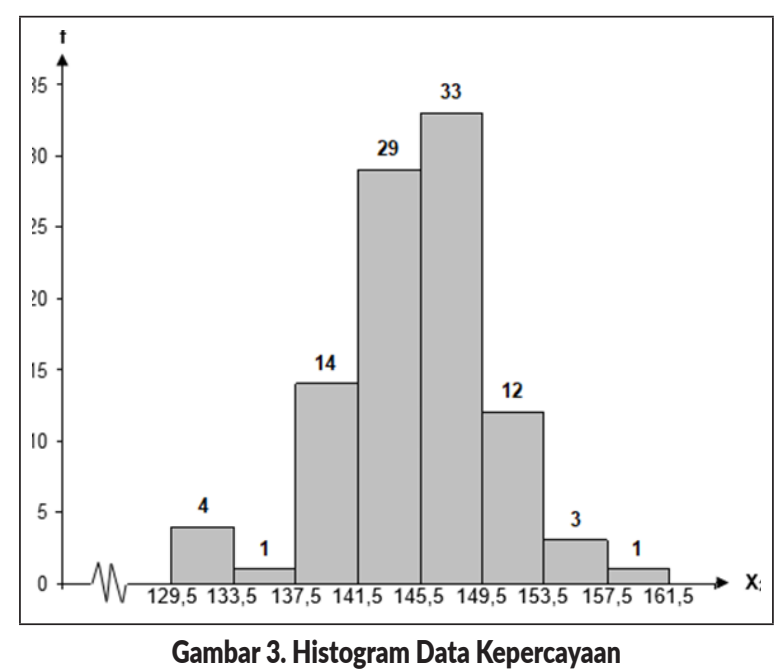

\section{B. Pengujian Hipotesis}

Berdasarkan hasil analisis pada bagian proses perhitungan yang dilakukan pada lampiran, dapat dirangkum berikut ini.

\section{Tabel 4. Matriks Koefisien Korelasi Sederhana antar Variabel}

\begin{tabular}{|c|c|c|c|}
\multirow{2}{*}{ Matrik } & \multicolumn{3}{|c|}{ Koefisien Korelasi } \\
\cline { 2 - 4 } & $\mathrm{X}_{1}$ & $\mathrm{X}_{2}$ & $\mathrm{X}_{3}$ \\
\hline $\mathrm{X}_{1}$ & 1,00 & 0,310 & 0,454 \\
\hline $\mathrm{X}_{2}$ & & 1,00 & 0,459 \\
\hline $\mathrm{X}_{3}$ & & & 1,00 \\
\hline
\end{tabular}

Berdasarkan tabel di atas dapat tergambarkan bahwa korelasi antara efektivitas manajerial dengan kepercayaan mendapatkan angka sebesar 0,310. Sedangkan korelasi antara efektivitas manajerial dengan kinerja mendapatkan nilai sebesar 0,454 . Yang terakhir korelasi antara kepercayaan dengan kinerja mendapatkan nilai sebesar 0,459.

\begin{tabular}{|c|c|c|c|}
\hline Hipotesis & $X_{1}$ & $X_{2}$ & $X_{3}$ \\
\hline $\begin{array}{l}\text { Efektivitas manajerial } \\
\text { berpengaruh } \\
\text { langsung positif } \\
\text { terhadap Kinerja }\end{array}$ & $\begin{array}{l}H_{0}: \beta_{31}<0 \\
H_{1}: \beta_{31}>0\end{array}$ & $\mathrm{H}_{0}$ ditolak & $\begin{array}{l}\text { Berpengaruh } \\
\text { langsung positif }\end{array}$ \\
\hline $\begin{array}{l}\text { Kepercayaan } \\
\text { berpengaruh } \\
\text { langsung positif } \\
\text { terhadap kinerja }\end{array}$ & $\begin{array}{l}\mathrm{H}_{0}: \beta_{32}<0 \\
\mathrm{H}_{1}: \beta_{32}>0\end{array}$ & $\mathrm{H}_{0}$ ditolak & $\begin{array}{l}\text { Berpengaruh } \\
\text { langsung positif }\end{array}$ \\
\hline $\begin{array}{l}\text { Efektivitas manajerial } \\
\text { berpengaruh } \\
\text { langsung positif } \\
\text { terhadap kepercayaan }\end{array}$ & $\begin{array}{l}\mathrm{H}_{0}: \beta_{21}<0 \\
\mathrm{H}_{1}: \beta_{21}>0\end{array}$ & $\mathrm{H}_{0}$ ditolak & $\begin{array}{l}\text { Berpengaruh } \\
\text { langsung positif }\end{array}$ \\
\hline
\end{tabular}

Ringkasan model analisis jalur dapat terlihat pada gambar berikut:

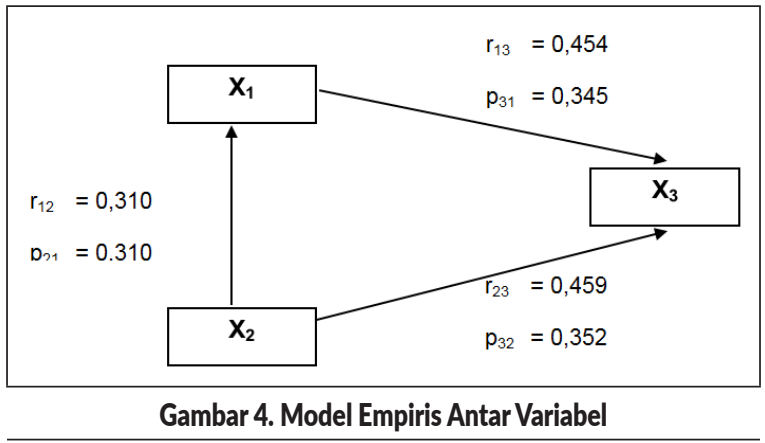

\section{Pembahasan Hasil Penelitian}

Melihat tinjauan pustaka dan sudah dibahas dan dikaji secara empiris maka langkah selanjutnya akan membahas hasil penelitian dengan mengkaitkannya antar hasil penelitian dan teori yang dikemukakan. Berikkut ini pembahasan secara rinci mengenai analisis dan pengujian hipotesis yang dapat diuraikan dibawah ini

1. Pengaruh Efektivitas Manajerial terhadap kinerja

Berdasarkan hasil pengujian hipotesis penelitian pertama mendapatkan kesimpulan bahwa adanya pengaruh langsung secara positif antara efektivitas manajerial terhadap kinerja guru dengan nilai koefisien korelasi sebesar 0,454 dan nilai koefisien jalur sebesar 0,345 . Ini menggambarkan bahwa efektivitas 
Manajerial dapat memempengaruhi secara langsung pada kinerja .

Dari hasil penelitian yang ditemukan ini senada dengan pendapat ahli John R. Schermerhorn (1998:28) yang mengatakan Truly effective managers create opportunities for individuals and groups to make high performance contributions in organizations and to experience satisfaction in the process. Jika dijelaskan kembali bahwa keefektivitasan manajerial mampu menciptakan suasana kerja bagi individu yang menginginkan organisasinya maju. Dengan demikian maka teori yang mengatakan bahwa adanya pengaruh pemimpin yang efektif dengan terciptanya capaian kerja yang baik. Sedangkan Laurie J. Mullins (2005 : 252) juga mendefinisikan bahwa There are a number of basic, underlying philosophies which are likely to make for the successful management of people and lead to improves work performance. Pada intinya Laurie mengatakan bahwa keberhasilan manajemen itu bisa menjadikan gambaran adanya kinerja individu yang baik pada organisasi. artinya teori ini mendukung atas hasil penelitian yang didapatkann. Bagaimana dengan Stephen P. Robbins (2007 : 538) yang mengatakan bahwa Managerialandleadership effectiveness depends on the ability to gain the trust of followers. Efektivitas manajerial dan kepemimpinan tergantung pada kemampuan untuk mendapatkan kepercayaan dari pengikut. Bahwa kepemimpinan efektivitasnya bagus dalam menjalankan organisasi sangat mampu menciptakan atau meningkatkan kemampuan anggota organisasinya. Sedang pernyataan tegas Robert D. Costigan juga mendefinisikan Leaders succeed in bringing about change because they are trusted by constituents to reflect their values and aspirations. Pemimpin yang berhasil membawa perubahan pada organisasinya karena adanya saling percaraya satu sama lain. Pemimpin yang baik hebat dalam memimpin organisasinya adalah karena mereka dipercaya oleh konstituen untuk mencerminkan nilai-nilai dan aspirasi mereka.
2. Pengaruh Kepercayaan atas Kinerja

Berdasrkan hasil pengujian hipotesis penelitian pertama mendapatkan kesimpulan bahwa adanya pengaruh langsung secara positif antara keprcayaan terhadap kinerja guru dengan nilai koefisien korelasi sebesar 0,459 dan nilai koefisien jalur sebesar 0,352. Ini menggambarkan bahwa kepercayaan dapat memempengaruhi secara langsung pada kinerja.

Hasil penelitian ini senada dengan pendapat beberapa ahli di antaranya adalah Jason A. Colquitt, Jeffery A (2009 : 240) menyatakan bahwa trust does affect job performance. One reason is that trust is moderately correlated with task performance. organisasi yang mampu menciptakan situasi emosional yakni kepercayaan dengan satu sama lain maka hal ini dapat menimbulkan rasa ingin untuk memiliki kinerja yang baik. Maka Colquitt mengatakan bahwa kepercayaan dapat mempengaruhi kinerja. Tokoh lain seperti Stephen P. Robbins (2011: 431) mengungkapkan bahwa employees who trust their supervisors tends to receive higher performance ratings. Leaders who break the psychological contract with workers, demonstrating they aren't trustworthy, will find employees are less satisfied and less committed, have higher intentions to turnover, engage in less citizenship behavior, and have lower task performance.

Bagiseorang pekerja bahwa mempercayai atasan bahwa atasan bisa memberikan kontribusinya dalam memimpin organisasi dapat meningkatkan kinerja karyawan tersebut. Karena tidak mungkin suatu organisasi yang bekerja dengan memiliki rasa tujuan yang sama tanpa memiliki rasa percaya satu sama lain. Hal jika dicontohkan pada saat karyawan masuk sebagai pengikut maka pada dasarnya karyawan dipercaya memiliki kemampuan dalam mencapai tujuan organisasi. Robert D. Costigan (1998) Leaders succeed in bringing about change because they are trusted by constituents to reflect their values and aspirations. Pemimpin berhasil membawa 
perubahan karena mereka dipercaya oleh konstituen untuk mencerminkan nilai-nilai dan aspirasi mereka.

3. Pengaruh Efektivitas Manajerial atas Kepercayaan

Berdasarkan hasil pengujian hipotesis penelitian pertama mendapatkan kesimpulan bahwa adanya pengaruh langsung secara positif antara efektivitas manajerial terhadap kepercayaan guru dengan nilai koefisien korelasi sebesar 0,310 dan nilai koefisien jalur sebesar 0,310. Ini menggambarkan bahwa efektivitas manajerial dapat mempengaruhi secara langsung pada kepercayaan.

Data hasil penelitian ini senada dengan pendapat beberapa ahli di antaranya adalah Christopher F. Achua (2010: 35 ) menyatakan bahwa, Integrity is essential to running a successful business. Our integrity affects our behavior. To be viewed as trustworthy, leader need to be honest, support their followers, and keep confidences. If followers find out their leader has been dishonest or in some way manipulated them for personal gain, the leader will lose the followers' trust. Integritas penting untuk menjalankan bisnis yang sukses. Dengan kita memiliki saat bekerja maka akan mampu mempengaruhi perilaku dalam bekerja. Pemimpin yang mampu bekerja dengan efektif maka akan meningkatkan perilaku kerja individu seperti legitimasi dari anggota atas pekerjaannya. Mengapa posisi manajer itu sangat penting karena sebagai variabel eksogen dapat menentukan arah dari organisasi.

\section{SIMPULAN}

Melihat hasil pengujian hipotesis yang sudah dilakukan dan atas pembahasan yang sudah dikemukakan maka memperoleh kesimpulan penelitian sebagai berikut: (1) efektivitas manajerial dapat mempengaruhi secara langsung dan positif terhadap kinerja guru, hal ini terlihat bahwa efektivitas manajerial yang tinggi akan meningkatkan kinerja guru di sekolah, maka semakin tinggi kemampuan efektivitas manajerial maka akan semakin tinggi juga kinerja guru SD Negeri Kecamatan Cabangbungin, Kabupaten Bekasi. (2) variabel kepercayaan berpengaruh langsung secara positif terhadap kinerja guru, hal ini dapat terlihat bahawa terciptanya kepercayaan yang baik itu maka akan mampu meningkatkan kinerja guru SD Negeri Kecamatan Cabangbungin, Kabupaten Bekasi. (3) Efektivitas manajerial dapat mempengaruhi langsung secara positif terhadap kepercayaan, ini bisa terlihat dari teori-teori yang dikemukan dan juga dilihat dari hasil olah data penelitian menunjukkan bahwa efektivitas manajerial yang tinggi dapat mempengaruhi kepercayaan, dan pengakuan atas kerja guru dan pemberian apresiasi atas hasil kerja guru.

\section{DAFTAR PUSTAKA}

Christopher F. A. dan Robert N. L. (2010). Effective Leadership 4th Edition (South-Western: Cengage Learning.

Gary Y. (2010). Leadership in Organizations 7th edition. New Jersey: Pearson Education, Inc.

James L.Gibson et.al. (2012). Organizations behavior, structure, process, Fourteenth Edition. New York: Mc.Graw Hill.

Jarunne S. et al. (2010). Factors Affecting Preceived Job Performance Among Staff: A Case Study Of Ban Karuna Juvenile Vocational Training Centre For Boys. The Journal Of Behavioral Science.

Jason A. Colquitt, J. LePine, dan Michel J. W. (2015). Organization Behavior, Improving Performance and Commitment in Workplace. New York: McGraw-Hill/Irwin.

Jason A. Colquitt, Jeffery A. LePine, Michael J. W. (2015). Organizational Behavior Improving Performance and Commitment in the Workplace 4 th edition. New York: Mc Graw Hill..

Jennifer M G., Gareth J. (2014). Contemporary Management Global Edition. New York: McGraw Hill.

John M. I, Robert K, Michael T. M. (2014). Organizational behavior and management. New York: McGraw Hill.

John R. S., Jr., James G. Hunt, Richard N. Osborn. 
(1998). Basic Organizational Behavior 2nd edition. New York: John Wiley \& Sons, Inc.

Laurie J. M. (2005). Management and Organisational Behaviour $7^{\text {th }}$ Edition. England: Pearson Education Limited.

Laurie J. M. (2005). Management and Organisational Behaviour 7th Edition. England: Pearson Education Limited.

Laurie J. M. (2005). Management and Organisational Behaviour 7th Edition. England: Pearson Education Limited.

Robert D. Costigan, et al. (1998). A MultiDimensional Study of Trust in Organizations. Journal of Managerial Issues Vol.X No.3.

Shalini S. (2011) Job burnout and managerial effectiveness relationship: Moderating effects of locus of control and perceived organisational support: an empirical study on Indian managers. Asian Journal of Management Research Vol. 2 (1).

Stephen P R., Mary C. (2014). Management Twelfth edition. New York: McGraw Hill.

Stephen P. R., Timothy A. J.(2011). Organizational Behavior 14th Edition. New Jersey: Pearson Education, Inc.

Steve M.Jex. (2002). Organizational Psychology. USA: John Wiley.

Steven L. Mc Shane, Mary Ann Von Glinow. (2010). Organizational Behavior Emerging Knowledge And Practice for the real World. New York: McGraw Hill.

Umesh K. Bamel, et.al. (2011). Managerial Effectiveness in Indian Organisations: Reexamining an Instrument in an Indian Context. Research and Practice in Human Resource Management, Vol. 19 (1). 